\title{
MICROEXTRAÇÃO EM FASE SÓLIDA: FUNDAMENTOS E APLICAÇÕES EM ANÁLISE DE ALIMENTOS
}

\author{
LEILA MARTINS DA COSTA QUINTEIRO * \\ ANA LÚCIA DA ROCHA NOBRE ** \\ AURÉLIO BAIRD BUARQUE FERREIRA ** \\ RONOEL LUIZ DE OLIVEIRA GODOY *** \\ IZABELA MIRANDA DE CASTRO ***
}

\begin{abstract}
No presente trabalho são apresentados os principais aspectos teóricos, funcionais e analíticos, da Microextração em Fase Sólida (MEFS), dedicando-se um tópico especial para sua aplicação em análise de alimentos. São descritas as principais características da instrumentação, das etapas de extração e das formas operacionais. Mostra-se o desenvolvimento de método de análise por MEFS aliado à cromatografia a gás (CG) e algumas aplicações em análise de alimentos, sendo discutidas as principais vantagens oferecidas pela técnica. Concluiu-se que a MEFS permite a extração, sem o uso de solventes, e a determinação de uma série de substâncias de matrizes sólidas, líquidas ou gasosas de modo prático e eficiente. $O$ uso crescente de MEFS-CG na detecção de fraudes, adulterações e contaminações de alimentos interessa aos órgãos fiscais responsáveis pela saúde pública.
\end{abstract}

PALAVRAS-CHAVE: MICROEXTRAÇÃO EM FASE SÓLIDA; ANÁLISE DE ALIMENTOS.

\section{INTRODUÇÃO}

O amplo uso de solventes orgânicos (normalmente tóxicos) que ocorre nas extrações líquido-líquido (ELL), ou Liquid-Liquid Extraction (LLE), vem impulsionando pesquisas sobre métodos de extração de compostos

* Professora Assistente e Doutoranda do Instituto de Ciências Exatas (ICE), Departamento de Química (DEQUIM), Universidade Federal Rural do Rio de Janeiro (UFRuRJ), Seropédica, Brasil (e-mail: quinteiro@ufrrj.br).

** Professor Adjunto, Doutor do ICE, DEQUIM, UFRuRJ, Seropédica, Brasil (e-mail: lucia.nobre@infolink.com.br; aureliof@ufrrj.br).

*** Pesquisador, Embrapa Agroindústria de Alimentos, Rio de Janeiro, RJ, Brasil (e-mail: ronoel@ctaa.embrapa.br; imcastro@ctta.embrapa.br). 
orgânicos que apresentem menor impacto sobre o homem e o meio ambiente. Métodos que usam gases inertes além do ponto crítico como fluido extrator e outros que usam uma fase sólida (como suporte ou como fase estacionária extratora) aproximam-se desse ideal. $O$ método de extração por fluido supercrítico (EFSC), ou Supercritical Fluid Extraction (SFE), apresenta como desvantagem o uso de grandes quantidades de $\mathrm{CO}_{2}$ de alta pureza (ou gás equivalente) tornando a análise muito dispendiosa, além de consumir muito tempo e não existir sistema extrator portátil. O segundo método (fase sólida), além de exigir pouco ou nenhum solvente, apresenta baixo custo, rapidez e a instrumentação pode ser transportada facilmente. Também possibilita concentrar vários analitos de interesse, simultaneamente, e permite determinações em níveis de detecção da ordem de ng/L, constituindo opção apropriada e eficiente para substituir extrações clássicas, como a ELL (1 - 2). São duas as técnicas alternativas de extração que utilizam o método em fase sólida. A primeira a surgir foi denominada de extração em fase sólida (EFS) ou Solid Phase Extraction (SPE) e a variante, mais recente, é conhecida como microextração em fase sólida (MEFS) ou Solid Phase Microextraction (SPME).

A MEFS é considerada como microtécnica de extração e de préconcentração de analitos, pois esses processos são realizados em escala muito pequena. VALENTE e AUGUSTO (3) descreveram a seguinte analogia para ilustrar o que ocorre em termos de escala. Uma gotícula de solvente orgânico de $1 \mu \mathrm{L}$ seria colocada em $10 \mathrm{~mL}(10.000 \mu \mathrm{L})$ de solução aquosa, contendo os analitos que se deseja analisar. Essa gotícula, que representa $0,01 \%$ do volume total, permaneceria imiscível na matriz, mesmo sob agitação. Analitos orgânicos, por sua afinidade com a gotícula, migrariam da matriz para a mesma, concentrando-se em seu interior de acordo com os coeficientes de partição gotícula/matriz. Após determinado tempo, a gotícula (impregnada de analitos) seria retirada do seio da matriz e levada para o interior do cromatógrafo para ser analisada. Como vantagem, a concentração da matriz permaneceria a mesma devido à pequena quantidade extraída de analito (comparativamente). Desse modo, outras extrações poderiam ser realizadas na mesma matriz para dispor de replicatas estatisticamente confiáveis. Na MEFS, a gotícula é representada por microcamada polimérica que reveste $1 \mathrm{~cm}$ da superfície de pequeno segmento de fibra ótica de sílica fundida. Tal camada, com volume de 0,03 a $0,7 \mu \mathrm{L}$ e espessura de 7 a $100 \mu \mathrm{m}$, é considerada a fase estacionária imobilizada em suporte de fibra com $300 \mu \mathrm{m}$ de diâmetro externo e $4,5 \mathrm{~cm}$ de comprimento (3). Durante a amostragem, a fibra revestida é exposta no seio da matriz para entrar em contato com os analitos que, por partição, serão concentrados na fase estacionária. Em determinado 
momento, a fibra revestida é removida da amostra e inserida no cromatógrafo. A técnica de MEFS foi desenvolvida entre 1989 e 1990 pelo Prof. Janusz Pawliszyn, da Universidade de Waterloo em Ontário (Canadá), para uso em cromatógrafo a gás (CG), em análises de poluentes orgânicos voláteis e semivoláteis em águas (4). Desde então, foram publicados vários tratamentos teóricos que fundamentam a técnica e trabalhos sobre a aplicação da MEFS em análises de amostras ambientais, de alimentos, forênsicas e botânicas, incluindo o uso de cromatógrafo líquido de alta eficiência (CLAE).

Esta revisão pretendeu descrever os principais aspectos que compõem a técnica de microextração em fase sólida (MEFS), o instrumento microextrator, os diversos modos e procedimentos de extração e os principais parâmetros usados no desenvolvimento de métodos analíticos. Também visou abordar as vantagens do uso da MEFS e suas aplicações na área de alimentos.

\section{INSTRUMENTO PARA A MEFS}

O instrumento completo para a microextração, denominado de amostrador (Figura 1), é composto por corpo cilíndrico com fenda (em "Z"), pela qual o pino travador desliza. Esse apresenta em sua extremidade superior um lançador e na inferior uma agulha oca de aço inoxidável (inox), com $560 \mathrm{~mm}$ de diâmetro externo. A agulha forma o canal que armazena toda a extensão da fibra e parte do tubinho inox. A outra extremidade do tubinho é envolta por uma pequena mola, e fica em contato com o lançador, obedecendo ao seu mecanismo da seguinte forma: o lançador, ao ser pressionado, empurra o tubinho, comprimindo a mola e, como conseqüência, a fibra desliza pela agulha e se expõe ao meio externo, ou se esconde, quando é puxada. O pino travador, fixado no lançador, acompanha esse movimento, na extensão da fenda em " $Z$ ". Quando posicionado no centro dessa fenda impede a subida do lançador, mantendo, assim, a fibra exposta (3).

A parte removível (Figura 2) do amostrador é composta pela agulha, pela fibra revestida e pela mola que envolve uma das extremidades do tubinho de inox. Seu diâmetro é semelhante ao da fibra colada na extremidade oposta, formando (aparentemente) segmento contínuo. O conjunto pode ser trocado de acordo com o seu estado de uso e com a natureza do analito que se deseja extrair. A fase estacionária polimérica que reveste a fibra e que funciona como "solvente" orgânico pode apresentar diferentes composições, várias polaridades e volumes. 


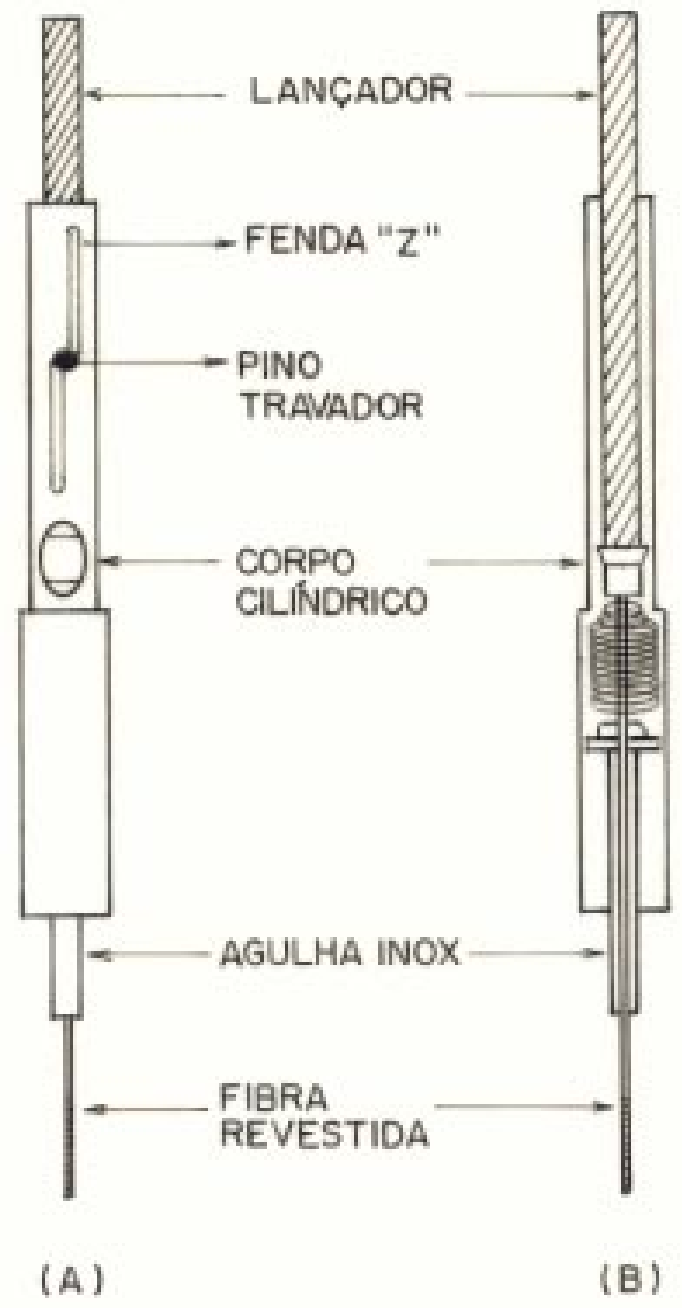

$A=$ Vista externa, mostrando a posição de trava (pino no centro da fenda) mantendo a fibra exposta; $\mathrm{B}=$ Vista interna, mostrando a parte removível com a fibra exposta. 
FIGURA 2 - PARTE REMOVÍVEL DO INSTRUMENTO PARA MEFS

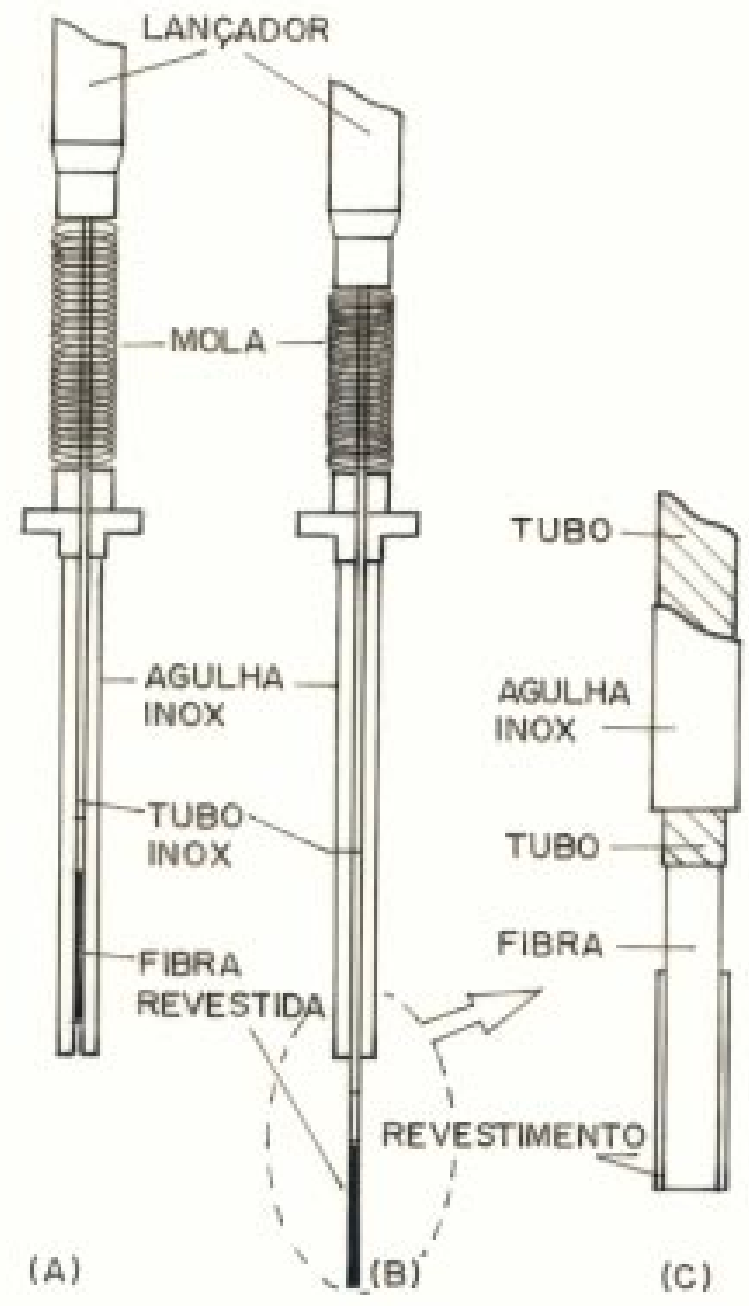

$A$ = Fibra escondida no interior da agulha; $B$ = Fibra exposta ao meio externo;

$\mathrm{C}=$ Detalhes da fibra revestida presa ao tubinho de aço inox. 
O dispositivo apresentado na Figura 2 foi projetado para que as fibras sejam retraídas para dentro da agulha durante as operações que possam danificá-las como as de transporte, perfuração do septo do frasco de amostra e do injetor do cromatógrafo (3-4).

Em vários trabalhos da literatura podem ser encontradas descrições sobre a construção artesanal de dispositivo de MEFS. Eram usadas fibras óticas de sílica fundida embutidas em seringas analíticas (de uso próprio para diluições) e, depois, ativadas na superfície exposta por reações com ácidos e polímeros (1,5-7).

Em 1992, LOUCH e colaboradores (7) usaram amostradores manufaturados pela sua equipe para análise simultânea de benzeno, tolueno e p-xileno, em águas. Nessa mesma época, a automação em MEFS-CG estava sendo introduzida mediante modificações no comprimento da agulha e do êmbolo de seringas Hamilton 7.005 e do uso de equipamento de Cromatografia a Gás (CG) modelo Varian 8100. CHAI e colaboradores descreveram, em 1993, como construíram o amostrador e analisaram hidrocarbonetos voláteis por MEFS. Os resultados experimentais indicaram que a microextração pode ser apropriadamente usada na análise de águas, de sólidos como o solo, de soluções gasosas como o ar, de óleos e de fluidos humanos empregando a técnica de MEFS em headspace (HS) (5-7).

Em 1993, os dispositivos para a microextração ainda eram feitos artesanalmente, geralmente com seringa de diluição Hamilton 7.105 (3, 8). Nesse mesmo ano, PAGE e LACROIX (9) descreveram um método HS-MEFS-CG para a determinação de 33 substâncias halogenadas voláteis. Em 1995, agrotóxicos em água, solo e vinho foram analisados por essa técnica (a maioria usando extração HS) com sucesso, sendo indicada para a investigação de analitos polares, não-polares, voláteis, semivoláteis e não-voláteis (10). Somente a partir daquele ano, os amostradores passaram a ser fabricados por firmas especializadas (11). Tal fato facilitou a execução das análises, tornando-as também mais precisas.

\section{REVESTIMENTOS POLIMÉRICOS - EVOLUÇÃO}

Não é comum a utilização de fibra ótica sem revestimento de filme especial. A extração, feita diretamente com o material (sílica fundida) que a constitui, ocorre sem muito critério. As fibras revestidas apresentam uso mais 
freqüente devido maior seletividade (semelhante dissolve semelhante) (12). Em 1992, fibras óticas revestidas já podiam ser encontradas no mercado. A Polymicro Technologies (Tuscon, AZ, USA) foi a primeira firma a produzilas com revestimento de polidimetilssiloxano (PDMS) nas espessuras de 56 e de $100 \mu \mathrm{m}$. No mesmo ano, cristais líquidos de poliacrilato (PA) começaram a ser testados $(7,13)$. Em 1995, três opções de fibras revestidas estavam disponíveis, PDMS de 7, de 30 e de $100 \mu \mathrm{m}$ de espessura. Em 1996 fibras revestidas com PA de $85 \mu \mathrm{m}$ juntaram-se às anteriores, sendo todas comercializadas pela Supelco (11-14). A espessura do revestimento e a sua natureza (polar, apolar ou bipolar) são as principais características que governam a seletividade e a eficiência da extração. Tais características são facilmente encontradas na literatura $(3-4,15)$ e em notas técnicas dos fabricantes (Tabela 1).

\section{TABELA 1 - REVESTIMENTOS COMERCIALMENTE DISPONÍVEIS E INDICAÇÕES DE USO (2)}

\begin{tabular}{|c|c|c|}
\hline $\begin{array}{c}\text { Revestimento espessura } \\
(\mu \mathrm{M})\end{array}$ & Natureza & Aplica I es sugeridas \\
\hline $\begin{array}{ll}\text { PDMS } & 7 \\
\text { PDMS } & 30 \\
\text { PDMS } & 100\end{array}$ & № o-polar & $\begin{array}{l}\text { Subst ncias apolares de alta massa molecular } \\
\text { Subst ncias semivol/fEeis } \mathrm{n}^{\mathrm{a}} \text { o polares } \\
\text { Subst ncias vol/姫is }\end{array}$ \\
\hline $\begin{array}{ll}\text { PA } 85 & \\
\text { CW/TR } & 50 \\
\text { CW/DVB } & 65 \\
\text { CW/DVB } & 70 \\
\text { Car/DVB } & 50 / 30\end{array}$ & Polar & 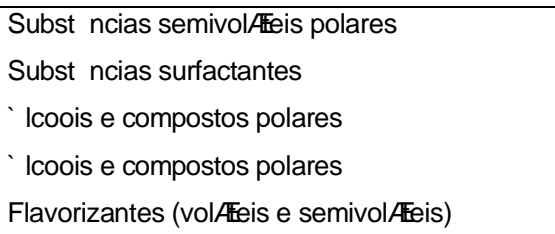 \\
\hline $\begin{array}{l}\text { PDMS/DVB } 60 \\
\text { PDMS/DVB } 65 \\
\text { PDMS/DVB } 65 \\
\text { Carboxen/PDMS } 75 \\
\text { Carboxen/PDMS } 85\end{array}$ & Bi-polar & 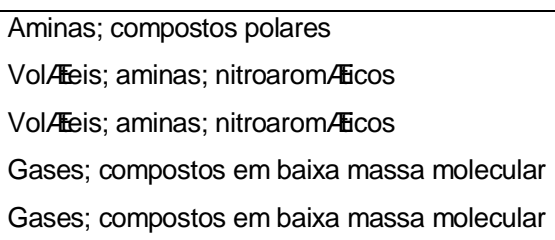 \\
\hline
\end{tabular}

PDMS = polidimetilssiloxano $; \mathrm{CW}=$ carbowax DVB = divinilbenzeno $\mathrm{PA}=$ poliacrilato .

Normalmente, os revestimentos com grande afinidade pelo analito (alta seletividade) e mais espessos (extraem em maior quantidade) proporcionam ao método alta sensitividade (13). 


\section{ETAPAS QUE COMPÕEM A TÉCNICA DE MEFS}

A operação da microextração (MEFS) compreende a extração e a dessorção (4). A extração do analito é a primeira etapa do processo e ocorre quando a fase estacionária (a fibra revestida) entra em contato com a matriz (Figura 3). No final da extração o amostrador é levado para a segunda etapa do processo. A dessorção ocorre quando os analitos, adsorvidos na fase estacionária, são expulsos e carreados para subseqüente análise cromatográfica. O processo de dessorção pode ser térmico, em CG, ou efetuado por solventes na interface MEFS-CLAE (4).

\section{FIGURA 3 - ESQUEMA SEQÜENCIAL DA EXTRAÇÃO POR MEFS}

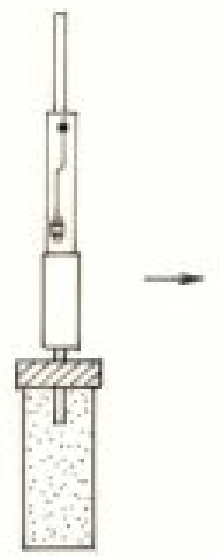

(19)

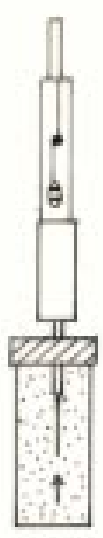

(2\%)

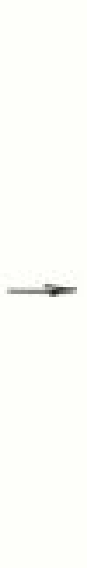

(3⿻)

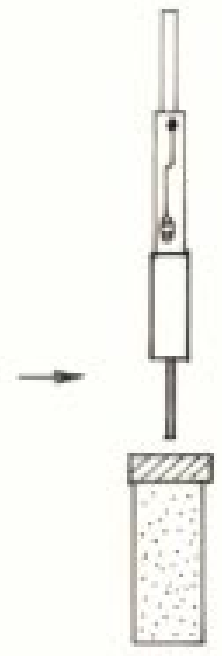

(4\%)

$1^{\circ}=$ Perfuração do septo, que veda o frasco que contém a amostra, pela agulha do amostrador; $2^{\circ}=$ Exposição da fibra no seio da matriz, por determinado tempo, para processar a extração de analitos; $3^{\circ}=$ Recolhimento da fibra para dentro da agulha; $4^{\circ}=$ Retirada da agulha.

A Figura 4 representa o esquema da seqüência operacional para a dessorção térmica. 
Excelentes sinais cromatográficos são produzidos quando são utilizados altos fluxos de gás carreador (na temperatura máxima permitida pela estabilidade do revestimento) em CG e de solvente carreador em CLAE $(4,15)$.

\section{FIGURA 4 - ESQUEMA SEQÜENCIAL DA DESSORÇÃO EM CG}

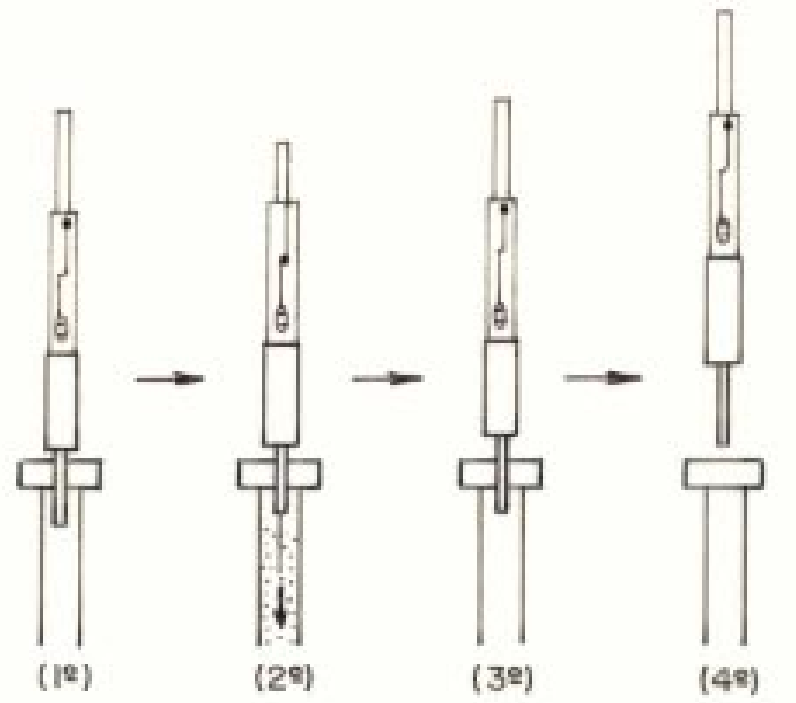

$1^{\circ}=$ Perfuração do septo do injetor do cromatógrafo; $2^{\circ}=$ Exposição da fibra, por tempo determinado, para processar a dessorção de analitos; $3^{\circ}=$ Recolhimento da fibra para dentro da agulha; $4^{\circ}=$ Retirada da agulha.

\section{MODOS DE SE OPERAR A MEFS}

De acordo com a forma de contato entre a fibra e os analitos existem dois modos para realizar a extração por MEFS, ou seja, direto ou em HS. A escolha deve ser feita em função, principalmente, do estado físico da matriz, da afinidade do analito com a matriz e de sua volatilidade. A extração também pode ser realizada com e sem agitação (4).

Na extração pelo modo direto a fibra revestida é inserida no seio da amostra (líquida ou gasosa) e os analitos (voláteis ou não), nela dispersos, são 
transportados para a fase extratora (Figura 1). Um modo variante da abordagem direta é o uso de fibras envolvidas por membrana protetora. Isso evita danos no revestimento da fibra devido à aderência de substâncias de alta massa molecular que possam estar presentes na amostra (4).

Em HS, a fibra revestida é inserida no espaço acima da amostra (sólida ou líquida) contida em frasco muito bem selado para que ocorra a extração de analitos voláteis ou semivoláteis $(4,11,14)$. Como a fibra não entra em contato com a amostra diretamente, o modo HS representa alternativa para extrações em amostras particuladas. Permite também modificações na matriz, como mudança de pH e concentração de sal, sem prejudicar a fase extratora. Em comparação com o modo direto, o HS exige menos tempo para atingir o equilíbrio de extração $(4,8,12)$.

A agitação, no momento da amostragem por MEFS, é na maioria das vezes necessária para facilitar o transporte dos analitos para a fase estacionária e assim reduzir o tempo de equilíbrio. A agitação magnética, dentre os meios de agitação existentes (magnética, intrusiva, por agitador Vortex, por fluxo, por sonicação e por vibração da fibra) é mais usada pela simplicidade (não necessita de dispositivos complexos e não adultera a amostra). A extração sem agitação pode proporcionar bons resultados quando os analitos são voláteis e colhidos em HS $(3,4)$.

\section{PRINCIPAIS ASPECTOS ANALÍTICOS - FUNDAMENTOS}

Sob o ponto de vista analítico não se deve esquecer que o polímero, que reveste a fibra para a microextração, pode ser considerado fase líquida imobilizada em contato com outra (a amostra), competindo entre si pela solubilização do analito (4). Logo, os fatores que afetam a eficiência das extrações líquidas convencionais ELL também atingem a MEFS $(4,7)$. Alguns desses fatores como volume, concentração e coeficiente de partição relacionam-se por uma equação analítica fundamental. Outros, apesar de independentes como a temperatura e o $\mathrm{pH}$, afetam a eficiência da extração, pois agem diretamente nas propriedades do fenômeno de partição.

\subsection{EQUAÇÃO ANALÍTICA FUNDAMENTAL}

Na MEFS, em sistemas bifásicos, ocorre a partição do analito entre a fase estacionária (revestimento da fibra) e o meio no qual o analito se 
encontra (fase aquosa). Após algum tempo, característico de cada analito, o equilíbrio de partição é estabelecido. Nesse momento, a extração direta pode ser avaliada quantitativamente mediante equação fundamental $(1,4$, $6-8,10-11,15-16)$ :

$$
n_{E S}=\frac{K_{E S / A Q} \cdot V_{E S} \cdot C_{0} \cdot V_{A Q}}{V_{A Q}+K_{E S / A Q} \cdot V_{E S}}
$$

Na qual:

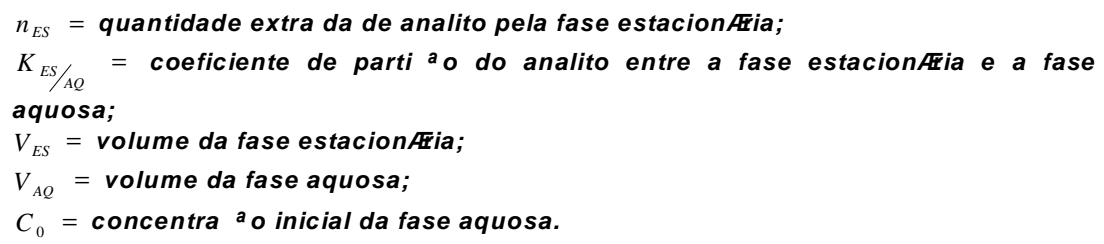

$\mathrm{O}$ volume da fase estacionária $\left(\mathrm{V}_{\mathrm{ES}}\right)$ geralmente é considerado como proporcional à espessura do revestimento, pois a área da fibra revestida é constante. Assim, $\mathrm{V}_{\mathrm{ES}}$ será máximo quando a espessura do revestimento for máxima e, quanto maior, maior será a quantidade extraída de analito. Já o volume de amostra $\left(\mathrm{V}_{\mathrm{AQ}}\right)$ submetido à extração pode ser muito pequeno, da ordem de poucos mililitros, ou muito menos. Tais variáveis, junto com o coeficiente de partição $\left(\mathrm{K}_{\mathrm{ES} / \mathrm{AQ}}\right)$ relacionam-se de forma muito interessante e conveniente.

$O V_{A Q}$ deve ser sempre otimizado experimentalmente, mas recomendase que seja maior do que $100 \mathrm{~mL}$ quando forem usados, na extração, revestimentos com baixa afinidade pelo analito $\left(\mathrm{K}_{\mathrm{ES} / \mathrm{AQ}}<1.000\right)$. Nesse caso, tem-se aproximação na soma do denominador da equação fundamental: $K_{E S / A Q} \cdot V_{E S}+V_{A Q} \cong V_{A Q}$, e, assim, a equação (I) é simplificada e transformada na equação (II), tornando $n_{E S}$ independente de $V_{A Q}$, o que é importante em amostragens ambientais in situ:

$$
n_{E S}=K_{E S / A Q} V_{E S} \cdot C_{0}
$$


Há casos em que $n_{E S}$ pode depender, de forma direta, somente de duas variáveis: $\mathrm{V}_{\mathrm{AQ}}$ e $\mathrm{C}_{0}$. Isso ocorre quando são usados revestimentos com alto $V_{E S}$ e alta afinidade pelo analito $\left(K_{E S / A Q}>1.000\right)$. Entretanto, o $V_{A Q}$ da amostra precisa ser ao mesmo tempo, suficientemente, pequeno para se tornar variável desprezível na soma e ocorrer nova aproximação: $\mathrm{V}_{\mathrm{AQ}}+$ $\mathrm{K}_{\mathrm{ES} / \mathrm{AQ}} \cdot \mathrm{V}_{\mathrm{ES}} \cong \mathrm{K}_{\mathrm{ES} / \mathrm{AQ}} \cdot \mathrm{V}_{\mathrm{ES}}$. Nessa situação a equação (I) é simplificada na equação (III), não ocorrendo, desse modo, a partição: o analito migra todo, rapidamente, para o revestimento da fibra. Isto é vantajoso quando extrações exaustivas são desejadas:

$$
n_{E S}=V_{A Q} \cdot C_{0}
$$

O coeficiente de partição ou de distribuição representa a seletividade do revestimento com relação ao analito e sua interação com a matriz. $A$ seletividade é baseada nas diferenças de polaridade e de volatilidade. A eficiência do processo de extração será sempre dependente da afinidade do analito pelas fases $-\mathrm{K}_{\mathrm{ES} / \mathrm{AQ}}(1,4,7,15)$.

Conforme foi mostrado anteriormente, a sensibilidade da técnica depende de $\mathrm{K}$ do analito e da espessura do revestimento. Quando ambos são altos produzirão baixos limites de detecção. De acordo com PAWLISZYN (4), em sistema cuja agitação é perfeita, K é diretamente proporcional à quantidade extraída de analito. Essa constante pode ser determinada pelas equações, assumindo que a extração entre rapidamente em equilíbrio, ou estimada através do coeficiente de partição octanol/água $\left(\mathrm{K}_{\mathrm{o} / \mathrm{w}}\right)$. Encontrado facilmente na literatura (17), $\mathrm{K}_{\mathrm{o} / \mathrm{w}}$ é útil para prever a afinidade de polímeros não-polares, como o PDMS, por determinados compostos orgânicos (12). Compostos lipofílicos (não-polares) apresentam $\mathrm{K}_{\mathrm{o} / \mathrm{w}}$ altos e, assim, espera-se que os mesmos, ao serem extraídos por polímeros não-polares possam ser determinados com alta sensibilidade $(4,15)$.

Algumas vezes, a quantidade de analito extraída $\left(n_{E S}\right)$ deixa de ser função linear da $\mathrm{C}_{0}$, contrariando as equações fundamentais. Isto ocorre quando as extrações são feitas em matrizes com altas concentrações de analitos, resultando em alterações na porosidade dos revestimentos e prejudicando tanto o processo de extração quanto o de dessorção (4). 


\subsection{TEMPERATURA E COMPOSIÇÃO DA MATRIZ}

Existem vários estudos sobre a otimização dos fatores que afetam a precisão e a exatidão das análises $(4,8,15)$. Esses mostram que a temperatura e a composição da matriz aquosa (presença de interferentes que modificam a força iônica e/ou a polaridade) influenciam muito a afinidade do analito pelas fases e, conseqüentemente, tornam $\mathrm{K}$ maior ou menor. Com o aumento da temperatura da matriz, os analitos tendem a se desagregar movendo-se com maior velocidade para o headspace e resultando em extrações mais rápidas. Esse procedimento, entretanto, pode reduzir a quantidade extraída de analito devido ao aquecimento do revestimento que também ocorre indesejavelmente. A água tem sido aditivo efetivo para facilitar a extração, pois pode ser usada em altas temperaturas para remover e dissolver analitos não-polares como, por exemplo, os hidrocarbonetos poliaromáticos - HPA $(4,15)$.

A adição de sal exerce forte efeito sobre a eficiência de extração, que depende da natureza do analito e da concentração de sal. Em geral, o efeito de salting out se amplia com o aumento da polaridade do composto $(4,15)$.

$\mathrm{O}$ pH da amostra afeta o equilíbrio de dissociação do analito em meio aquoso. Assim, no caso de analitos ácidos, a diminuição do pH resulta em aumento na concentração das espécies neutras (menos solúveis em água) e na quantidade extraída. Na prática não se pode provocar alteração no $\mathrm{pH}$ quando se usa a extração direta, pois o contato da fibra revestida com soluções ácidas ou alcalinas diminui a vida útil da mesma (4, 12, 15).

Quando se usa MEFS - HS tem-se um sistema trifásico, cujas fases (matriz, revestimento e headspace) competem entre si pelos analitos e a equação fundamental passa a ser (4):

$$
n_{E S}=\frac{K_{E S / A Q} \cdot V_{E S} \cdot C_{0} \cdot V_{A Q}}{K_{H S / A Q} \cdot V_{H S}+V_{A Q}+K_{E S / A Q} \cdot V_{E S}}
$$


Os novos termos $\mathrm{K}_{\mathrm{HS} / \mathrm{AQ}}$ e $\mathrm{V}_{\mathrm{HS}}$ correspondem ao coeficiente de partição do analito entre o headspace e a amostra e ao volume do headspace, respectivamente.

\section{DESENVOLVIMENTO E VALIDAÇÃO DE MÉTODO DE EXTRAÇÃO POR MEFS}

O conhecimento da teoria analítica que fundamenta a técnica MEFS orienta o estabelecimento de parâmetros que governam a sua eficácia, após otimização dos procedimentos experimentais de cada etapa. Tais procedimentos devem ser realizados com muito critério e as respostas obtidas numa etapa ajudam a delinear a próxima. O tipo e a espessura da fase extratora (polímero que reveste a fibra), os tempos de extração e de dessorção e a temperatura de dessorção determinados experimentalmente e, posteriormente, avaliados com testes de precisão constituem os principais parâmetros.

O tempo de extração ( $\mathrm{t}_{\mathrm{E}}$ ), variável extrínseca ao meio extrator, corresponde ao tempo de contato entre a fase extratora e a fase extraída para que os analitos sejam adsorvidos pela fibra revestida. Como ocorre com as variáveis das equações fundamentais, o $t_{E}$ é essencial para a otimização do método. A repetibilidade e a exatidão dos resultados são obtidas com maior facilidade quando o tempo de extração usado é suficiente para que o equilíbrio de adsorção seja alcançado. Esse tempo, denominado de tempo de equilíbrio ( longo. Para reduzir o tempo de análise usa-se $t_{E}<t_{\infty}$, que quando repetido com precisão também possibilita excelentes respostas. Quando $t_{E}=t_{\infty}$ (equilíbrio atingido) a concentração $\left(\mathrm{C}_{0}\right)$ do analito e a sua quantidade extraída no equilíbrio $\left(\mathrm{n}_{\mathrm{ES}}\right)$ poderão ser determinadas com auxílio de curva padrão (área $\times \mathrm{C}_{0}$ ), aplicando-se a concentração $\left(\mathrm{C}_{0}\right)$ e $\mathrm{K}$ em uma das equações do equilíbrio, respectivamente. Com os valores de $n_{E S}$ tem-se a opção de confeccionar outras curvas padrão (área $\times n_{E S}$ e/ou $n_{E S} \times C_{0}$ ) a partir da primeira. Quando $t_{E}<t_{\infty}$ (equilíbrio não-atingido) a concentração do analito também será determinada pela curva padrão (área $\times \mathrm{C}_{0}$ ). Já a quantidade extraída do analito ( $n_{E S}$ fora do equilíbrio) não poderá ser determinada por meio das equações I ou II, próprias do equilíbrio. Para esse fim, o sinal cromatográfico produzido será interpolado na curva padrão (área $\left.\times \mathrm{n}_{\mathrm{ES}}\right),(1,4,15)$.

LOUCH e colaboradores (7) afirmaram que o toé diretamente proporcional à espessura do revestimento e a massa molecular do analito em sistemas 
sob agitação. Isso devido à influência do coeficiente de difusão, que depende desses fatores. Assim, para a análise de não-voláteis é indicado o uso de revestimentos menos espessos. Para aumentar a sensibilidade, sem aumentar to, o ideal seria aumentar a área superficial do revestimento (comprimento ou diâmetro da fibra) e não a espessura do filme. Entretanto, essa opção geralmente não é possível na prática.

Para as dessorções térmicas serem quantitativas é necessário que a temperatura do injetor esteja acima da temperatura de ebulição do analito, mas sem ultrapassar a temperatura máxima suportável pelo material do revestimento da fibra $(5,6)$. Nessas condições ocorre redução (cerca de mil vezes) na afinidade do analito pelo revestimento $(4,15)$. O tempo de dessorção $\left(t_{D}\right)$ ideal é aquele que proporciona o maior e melhor sinal cromatográfico, produzido pelo analito ou o melhor perfil de sinais gerado pelo conjunto de analitos a serem determinados na mesma amostra. A determinação do $t_{D}$ geralmente é feita com altas velocidades de fluxo linear do gás carreador (CG) ou do solvente (CLAE) em torno do revestimento $(4,15)$.

A validação do método nos estudos quantitativos consultados é realizada pela linearidade, pela recuperação e pela repetibilidade. Envolve ainda a comparação dos resultados obtidos com os oriundos de métodos convencionais, a avaliação com amostras certificadas e comparação interlaboratorial $(3-4,15)$. Detalhes sobre validação são fornecidos pelos trabalhos de PAWLISZYN (4) e VALENTE e AUGUSTO (3).

\section{BREVE COMPARAÇÃO ENTRE AS TÉCNICAS DE EXTRAÇÃO E MICROEXTRAÇÃO EM FASE SÓLIDA (EFS E MEFS) (1-7)}

As principais diferenças entre a EFS e a MEFS são verificadas basicamente na apresentação da fase estacionária, nos procedimentos de extração e de dessorção e seus efeitos em relação às perdas e interferentes. É na fase estacionária que ocorre a adsorção, cuja forma de apresentação e manipulação pode facilitar essa etapa e contribuir ou não para a eliminação de impurezas interferentes. Seu tamanho em relação à amostra pode tornar a adsorção exaustiva, o que se reflete no tempo de análise. A MEFS, de acordo com a volatilidade do analito de interesse, permite que amostras sólidas possam ser analisadas diretamente com tratamento prévio mínimo. A dessorção, no caso da MEFS, ocorre no interior do cromatógrafo, dificultando a perda de analitos. Já na EFS, no momento da evaporação do solvente usado para a dessorção, há o risco 
de perdas e reações paralelas sensíveis ao calor, o que prejudica a análise. $\mathrm{Na}$ tabela 2 essas diferenças foram agrupadas para melhor comparação.

\section{TABELA 2 - EXTRAÇÃO EFS VERSUS MICRO-EXTRAÇÃO MEFS (1-7)}

\begin{tabular}{|c|c|c|}
\hline & EFS & MEFS \\
\hline $\begin{array}{l}\text { Fase } \\
\text { estacion/Fa }\end{array}$ & $\begin{array}{l}\text { Granulada, preenche tubo cil ndrico (de } \\
\text { pl/stico) e sua superf cie s lida extratora } \\
\text { apresenta geometria mais complexa do que } \\
\text { a do MEFS }\end{array}$ & $\begin{array}{l}\text { Micro-camada polimørica que reveste o } \\
\text { suporte de fibra tica de poucos } \mu \text { m de } \\
\text { di metro. Sua superf cie extratora de } \\
\text { geometria mais simples facilita a entrada } \\
\text { e a sa da dos analitos (extra }{ }^{a} 0 \text { e } \\
\text { dessor }{ }^{\stackrel{a}{0}} \text { ) }\end{array}$ \\
\hline $\begin{array}{l}\text { 1“ Etapa: a } \\
\text { extra }{ }^{\mathrm{a}} \mathrm{0} \text { : }\end{array}$ & $\begin{array}{l}\text { Realizada quando a amostra atravessa a } \\
\text { fase estacion/fia. Geralmente precisa de } \\
\text { tempo maior que a MEFS, pois o acesso dos } \\
\text { analitos } \varnothing \text { mais dif cil e esses devem ser } \\
\text { extra dos da matriz atØexaust }{ }^{\mathrm{a}} \text { o }\end{array}$ & 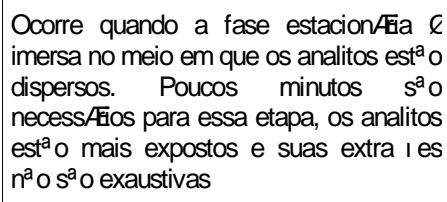 \\
\hline $\begin{array}{l}\text { 2“ Etapa: a } \\
\text { dessor } \stackrel{a}{\stackrel{a}{0}}\end{array}$ & $\begin{array}{l}\text { Ocorre fora do cromat grafo, quando a fase } \\
\text { estacion/Ea Øpercolada por solventes }\end{array}$ & $\begin{array}{l}\text { Ocorre dentro do cromat grafo. Pode ser } \\
\text { tømica no CG ou por solvente na CLAE }\end{array}$ \\
\hline $\begin{array}{l}\text { Perdas de } \\
\text { analito }\end{array}$ & $\begin{array}{l}\text { Ocorre quando os analitos } s^{\mathrm{a}} \text { o adsorvidos } \\
\text { pelas paredes do tubo (de pl/Astico), caso a } \\
\text { dessor a o seja incompleta ou for usado } \\
\text { aquecimento dr/stico para evaporar o } \\
\text { solvente }\end{array}$ & 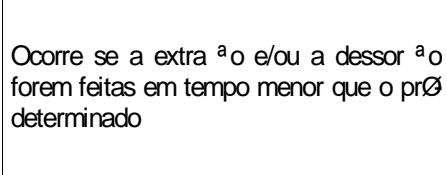 \\
\hline Amostra & Deve ser I quida ou estar em solu $\stackrel{a}{=} 0$ & $\begin{array}{l}\text { Deve gerar solu } \stackrel{a}{\circ} \text { aquosa ou gasosa } \\
\text { (headspace) }\end{array}$ \\
\hline Analitos & Fixos e semivol/Æeis & Fixos, semivol/Æeis e vol/Æeis \\
\hline InterferCGcias & $\begin{array}{l}\text { Podem ocorrer devido ao arraste de } \\
\text { mon meros do tubo de pl/Astico ou pela } \\
\text { forma }{ }^{a} \text { o de produtos durante a evapora }{ }^{a} 0 \\
\text { do solvente }\end{array}$ & $\begin{array}{l}\text { Podem ocorrer se a limpeza da fibra } n^{2} 0 \\
\text { for feita freq entemente }\end{array}$ \\
\hline
\end{tabular}

\section{VANTAGENS DA MEFS SOBRE AS TÉCNICAS CONVENCIONAIS}

Os procedimentos peculiares para execução da técnica MEFS, associados a métodos modernos de análise (CG, CLAE e detectores), permitem determinações em níveis de detecção da ordem de $\mathrm{ng} / \mathrm{L}$ com 
redução de até $70 \%$ no tempo necessário à preparação da amostra. Ao contrário das técnicas convencionais a MEFS praticamente não exige solventes de alto custo (geralmente tóxicos) e possibilita concentrar vários analitos de interesse, simultaneamente, sem o risco de produzir emulsão. Trata-se de técnica não-destrutiva, cuja extração está atrelada ao equilíbrio (não ocorre até exaustão), possibilitando que várias amostragens sejam efetuadas na mesma alíquota (volumes de amostra menores que $1 \mathrm{~mL}$ podem ser analisados com bons resultados). A seringa (amostrador), de baixo custo, é versátil (pode ser usada em CG e em CLAE), apresenta facilidade operacional (com automatização opcional) e é portátil (pode ser aplicada em campo) e a fibra revestida (um de seus acessórios descartáveis) pode ser reutilizada por mais de 50 vezes (2-4, 6-7).

\section{APLICAÇÃO DA MEFS EM ANÁLISE DE ALIMENTOS}

De 1990 a 1997 as pesquisas com MEFS estavam centradas, na maioria das vezes, nas determinações de poluentes em águas usando CG e técnicas de headspace. Esse método permite excelente sensibilidade para a análise de traços. Nesse mesmo período, muitos trabalhos teóricos para embasar a técnica também surgiram (18-37). A partir de 1997, a aplicação dessa técnica expandiu-se para maior diversidade de matrizes, tais como solo, ar, alimentos, plantas, cabelo, produtos farmacêuticos, saliva, urina e sangue (4). Em particular, pesquisas sobre a contaminação de alimentos por pesticidas usando extração por EFS e por MEFS resultaram em várias publicações entre 1992 e 2002. Substâncias orgânicas voláteis (SOV) são freqüentemente analisadas em bebidas alcoólicas como vinho (38-49), cervejas (50-52), vodka (53) e whisky (54), em bebidas nãoalcoólicas, como suco de frutas (55-64), café (65) e leite (66-67), em queijos (68-69), em méis (70), em óleos vegetais (71), e em carnes curadas (72). No caso de substâncias pouco ou não-voláteis têm-se, por exemplo a determinação de cafeína em bebidas (73-74), fenol em mel (75), isotiocianato (76) e estireno (77) em vinhos e agrotóxicos em méis (78$83)$, em morangos (84-86), em vinhos (10,87-88), em mostos (88), em vegetais comestíveis (89) e em leite (90). Pelo número de exemplos podese verificar que as aplicações da MEFS em alimentos estão, geralmente, associadas à determinação de SOV por HS-CG, mais especificamente, em análise de aromas (em bebidas, como vinhos, cervejas, vodka e sucos de frutas). A análise de voláteis por HS é prática, rápida, oferece maior duração da fibra e os resultados podem fornecer diversas informações.

A análise de substâncias orgânicas voláteis (SOV) pode ser útil na 
averiguação da autenticidade e da pureza dos alimentos e, até mesmo, de sua origem geográfica. Esse é o caso de azeites (71), cafés (66), vodkas (53), vinhos $(38,41,46)$ e de whisks $(54)$, todos com extração por MEFS. A composição dos alimentos, quanto às SOV, pode ser indicativa também do estado de conservação e da qualidade das etapas do processamento do alimento. A técnica de MEFS vem sendo usada para: a) avaliar a produção de metabólitos bacterianos voláteis no alimento e o surgimento de alterações no aroma característico (91-92) como indicativos da estabilidade do alimento e da eficácia da embalagem durante o seu armazenamento; b) acompanhar a produção de aromas agradáveis devido às reações de Maillard em processos de torrefação do cacau e farinhas (93-94) e de alterações indesejáveis no aroma provocadas por tratamentos térmicos de conservação (62, 95-96), ambas indicativas da influência que o calor exerce na qualidade de alimentos; c) avaliar as alterações na qualidade sensorial de sucos de laranja devido aos processos de clareamento (63) e de conservação por irradiação (97); d) caracterizar aromas agradáveis para avaliar o impacto produzido por culturas start na qualidade de produtos fermentados (98); e e) analisar o teor de alcoóis e ésteres em bebidas alcoólicas, sendo ambos parâmetros de qualidade da fermentação (51).

NONATO e colaboradores (99) apresentaram os resultados do desenvolvimento de método HS-MEFS para a determinação de compostos secundários de cachaças de cana-de-açúcar brasileiras. Alcoóis superiores e acetato de etila (dentre outros subprodutos da fermentação) são os mais importantes parâmetros indicativos da qualidade da cachaça. RUIZ et al. (100) reportaram que SOV desejáveis em carnes curadas, oriundas das degradações (oxidativas) de lipídios e de aminoácidos (degradação de Strecker), foram satisfatoriamente extraídas por HS-MEFS para determinação da qualidade do produto.

A técnica de MEFS mostrou-se aplicável na identificação de produtos em estado de deterioração pela determinação de SOV indesejáveis. Essas são responsáveis pelo odor desagradável, como aminas voláteis produzidas por microrganismos (101-102) e substâncias secundárias voláteis resultantes da peroxidação de ácidos graxos (100). MARSILI (67) investigou os estágios da fotoxidação lipídica em leite e acompanhou, por HS-MEFS, a formação de subprodutos voláteis dessa degradação (aldeídos, cetonas, ésteres e alcoóis de baixa massa molecular), pesquisa importante para a avaliação do estado de conservação do alimento.

A determinação da produção de SOV por MEFS também foi indicada 
para obter dados sobre o valor nutricional de alimentos e a segurança alimentar (quanto à presença de bactérias patogênicas e poluentes). WADA (103) estudou as alterações de óleos de peixe, ricos em ácidos graxos polinsaturados. Para a verificação das condições de potabilidade de águas VALENTE et al. (104) determinaram a presença de derivados tri-halometanos e JIA et al. (105) de clorofórmio. Contaminações por SOV, como benzeno e tolueno, foram investigadas por MEFS-CLAE com sucesso em suco de frutas (64) e em óleos vegetais comestíveis (106). $O$ grau de contaminação de alimentos por bactérias patogênicas, fontes potenciais de intoxicação e infecção alimentar, foi avaliado com sucesso pela determinação de SOV emitidas por tais microrganismos (107- 108).

Análises de SOV por MEFS podem constituir ferramenta alternativa em estudos de biossíntese, da especificidade de enzimas por determinados substratos (109) e em avaliações da eficiência da produção fúngica de aromas naturais, usados como aditivos em alimentos (110-111). Ao contrário da análise de voláteis por HS-MEFS, a aplicação da MEFS pelo modo direto em análise de resíduos não-voláteis ou semivoláteis em alimentos não é muito freqüente ainda que bons resultados tenham sido obtidos. Fato constatado pelo pequeno número de trabalhos publicados. A detecção de contaminações alimentares por substâncias com alta massa molecular como micotoxinas (112) e por metais, como o selênio (113-114) e o mercúrio (115), também são exemplos de aplicações que podem ser mais exploradas. Verificou-se que muitos trabalhos, mencionados anteriormente, reportam análises bem sucedidas de agrotóxicos em vinhos, em mostos, em diversas hortaliças, em morangos, em leite e em mel (116).

\section{CONSIDERAÇÕES FINAIS}

A técnica de MEFS é aplicável a qualquer forma de matriz (líquidos, sólidos e gases) com amostragem direta (sem a necessidade de preparo inicial de amostra), diminuindo os riscos de contaminação e o tempo de análise. A incorporação de padrão interno na matriz e o estabelecimento do tempo ótimo de extração resultam em correlações quantitativas, aumentando a sua precisão.

A MEFS é uma técnica fundamentada no equilíbrio entre adsorção e dessorção. A precisão da quantificação, quando são usadas as fases fora do equilíbrio, requer que as extrações sejam cuidadosamente controladas. Cada componente comporta-se diferentemente, dependendo 
da polaridade, da volatilidade, do coeficiente de partição, do volume de amostra ou do headspace, da velocidade de agitação, da composição da matriz, do pH e da temperatura. Como a extração por MEFS não utiliza solvente pode ser otimizada para que a amostra não necessite de aquecimento, dificultando a formação de produtos secundários que podem proporcionar erros nos resultados.

Através de dados da literatura consultada, no período de 1992 a 2002, verificou-se que a MEFS foi e continua sendo muito utilizada na análise de alimentos. Substâncias voláteis são as mais determinadas e com freqüência menor, porém crescente, as semivoláteis, como cafeína, ácidos graxos, estireno, fenol e agrotóxicos, dentre outras. Os dados indicam também que a MEFS pode se tornar importante nas investigações de metais, toxinas, vitaminas, açúcares simples e aminoácidos em alimentos.

Considerando que vários trabalhos mostram a eficiência do método MEFSCG na análise de agrotóxicos, esse poderia ser usado com maior freqüência e legitimado como oficial. A presença de agrotóxicos em alimentos envolve a saúde pública, sendo sua análise necessária devido aos limites residuais máximos estabelecidos pela Agência Nacional de Vigilância Sanitária (ANVISA). Matrizes como suco de frutas, vinhos, hortaliças e mel são as mais sujeitas às várias fontes de poluição. $A$ determinação de fraudes e adulterações pela análise de componentes característicos de identidade não-voláteis, usando métodos que envolvem a extração por MEFS também parece possível conforme a técnica for sendo desenvolvida.

\section{Abstract}

SOLID PHASE MICROEXTRACTION: FUNDAMENTALS AND APPLICATIONS IN FOOD ANALYSIS

In this work, the most important aspects, analytical, theoretical and functional, of Solid Phase Microextraction (SPME) are presented, with a special emphasis in food analysis applications. The main features instrumentation of extraction stages and of operational procedures are described. Furthermore, development of the analytical method employing SPME with gas chromatography (GC) and some applications to food analysis and the advantages offered by this technique are discussed. SPME is seen to provide practical and efficient extraction without solvent as well as the determination of many compounds contained in solid, liquid or gas matrices. The use of SPME-GC methods for detection of fraud, adulteration and contamination of food has been increased, and is of interest to the official public health institutions.

KEY-WORDS: SOLID-PHASE-MICROEXTRACTION; FOOD-ANALYSIS. 


\section{REFERÊNCIAS}

1 ARTHUR, C.L.; PAWLISZYN, J. SPME with thermal desorption using fused silica optical fibers. Analytical Chemistry, v. 62, p. 2145-2148, 1990.

2 GORECKI, T.; MINDRUP, R.; PAWLISZYN, J. Pesticides by solid-phases microextraction: results of a robin test. Analyst, v.10, n.10, p.1381-1386, 1996.

3 VALENTE, A.L.P.; AUGUSTO, F. Microextração por fase sólida. Química Nova, v.23, n.4, p. 523-530, 2000.

4 PAWLISZYN, J. Solid Phase Microextraction: theory and practice. New York: John Wiley \& Sons, 1997. 247 p.

5 ARTHUR, C.L.; KILLAM, L.; BUCHHOLZ, K.D.; PAWLISZYN, J. Automation and optimization of SPME. Analytical Chemistry, v.64, p.1960-1966, 1992.

6 CHAI, M.; ARTHUR, C.L.; PAWLISZYN, J.; BELARDI, R.; PRATT, K. Determination of volatile chlorinated hydrocarbons in air and water with SPME. Analyst, v. 118, p.1501-1505, 1993.

7 LOUCH, D.; MOTLAGH, S.; PAWLISZYN, J. Dynamics of organic compound extraction from water using liquid coated fused silica fibers. Analytical Chemistry, v.64, p.1187-1199, 1992.

8 ZHANG, Z.; PAWLISZYN, J. Headspace SPME. Analytical Chemistry, v.65, p.1843-1852, 1993.

9 PAGE, B.D.; LACROIX, G. Application of SPME to the headspace gas chromatographic analisys of semi volatile organochlorine contaminants in aqueous matrices. Journal of Chromatography A, v.757, p. 173-182, 1997.

10 BOYD-BOLAND, A.; PAWLISZYN, J. SPME of nitrogen containing herbicides. Journal of Chromatography, v.704, p. 163-172, 1995.

11 BARNABAS, I.J.; DEAN, J,R.; FOWLIS, I. A.; OWEN S.P. Automated determination of s-triazine herbicides using SPME. Journal of Chromatography, v. 705, n.2, p. 305-312, 1995.

12 EISERT, R.; LEVSEN, K. SPME coupled to gas chromatography: a new method for the analysis of organics in water. Journal of Chromatography A, v.733, n.1-2, p.143-157, 1996.

13 POTTER, D.W.; PAWLISZYN, J. Detection of substituted benzenes in water at the $\mathrm{pg} / \mathrm{mL}$ level using SPME and GC ion trap mass spectrometry. Journal of Chromatography, v. 625, p. 247-255, 1992.

14 MAGDIC, S.; BOYD-BOLAND, A.; JINNO, K.; PAWLISZYN, J. Analysis of organophosphorous insecticides from environmental samples by SPME. 
Journal of Chromatography A, v. 736, n.1-2, p. 219-228, 1996.

15 ARMON, A.D. Solid phase microextraction for the analysis of flavors. In: TECHNIQUES for analyzing food aroma. New York: Marcel Dekker, 1997. Cap 4, p. 81-112.

16 MAGDIC, S.; PAWLISZYN, J. Analysis of organochlorine pesticides using SPME. Journal of Chromatography A, v. 723, p. 111-122, 1996.

17 DEAN, J.; TOMLINSON, W. R.; MAKOVSKAYA, V., CUMMING, R.; HETHERIDGE, M.; COMBER, M. SPME as a method for estimating the Octanol-water partition coefficient. Analytical Chemistry, v. 68, n.1, p.130133, 1996.

18 ARTHUR, C. L.; PAWLISZYN, J. SPME with thermal desorption using fused silica optical fibers. Analytical Chemistry, v. 62, n.19, p. 21452148,1990 .

19 ARTHUR, C.L.; KILLAM, L. M.; BUCHHOLZ, K. D.; PAWLISZYN, J., BERG, J. R. Automation and optimization of SPME. Analytical Chemistry, v.64, n.17, p.1960-1966, 1992.

20 ARTHUR, C. L.; POTTER, D. W.; BUCHHOLZ, K. D.; MOTLAGH, S.; PAWLISZYN, J. SPME for the direct analysis of water: theory and practice, LC-GC, v.10, n.9, p.656, 658, 660-661, 1992

21 ARTHUR, C. L.; BUCHHOLZ, K. D.; POTTER, D. W.; MOTLAGH, S.; KILLAM, L.; PAWLISZYN, J. Practical and theoretical aspects of SPME for the direct analysis of groundwater. Proc. Water Qual. Technol. Conf., Pt.2, p.1315-1333, 1993.

22 BERG, J. R. Practical use of automated SPME. American Laboratory, v.25, n.17, p.18, 20, 22-24,1993.

23 ZHANG, Z.; PAWLISZYN, J. Headspace SPME. Analytical Chemistry, v.65, n.14, p.1843-1852, 1993.

24 ARTHUR, C. L.; BUCHHOLZ, K. D.; POTTER, D. W.; ZHANG, Z.; PAWLISZYN, J. Theoretical and practical aspects of SPME with thermal desorption using coated fused silica fibers. Natl. Meet. Am. Chem. Soc., Div. Environ. Chem., v.33, n.1, p.424-42, 1993.

25 HANG, Z.; YANG, M. J.; PAWLISZYN, J. SPME. A solvent-free alternative for sample preparation. Analytical Chemistry, v.66, n.17, p.844A-854A, 1994.

26 GORECKI, T.; PAWLISZYN, J. Sample introduction approaches for SPME - Rapid GC. Analytical Chemistry, v.67, n.18, p.3265-3274,1995.

27 GORECKI, T.; PAWLISZYN, J. SPME isothermal GC for rapid analysis of complex organic samples. J. High Resol. Chromatogr., v. 18, p.161166, 1995.

28 PAWLISZYN, J. New directions in sample preparation for analysis of 
organic compounds. Trends Anal. Chem v.14, n.3, p.113-122, 1995.

29 ZHANG, Z; PAWLISZYN, J. Quantitative extraction using an internally cooled SPME device. Analytical Chemistry, v.67, n.1, p.34-43,1995.

30 DAIMON, H.; PAWLISZYN, J. High temperature water extraction combined with SPME. Anal. Commun., v.33, n.12, p. 421-424, 1996.

31 GUO, F.; GORECKI, T.; IRISH, D.; PAWLISZYN, J. SPME combined with Electrochemistry. Anal. Commun., v. 33, n.10, p. 361-364,1996.

32 POERSCHMANN, J.; ZHANG, Z.; KOPINKE, F. D.; PAWLISZYN, J. SPME for determining the distribution of chemicals in aqueous matrixes. Analytical Chemistry, v. 69, n. 4, p. 597-600, 1997.

33 SARAULLO, A.; MARTOS, P. A.; PAWLISZYN, J. Water analysis by SPME based on physical chemical properties of the coating. Analytical Chemistry, v.69, n.11, p.1992-1998,1997.

34 BARTELT, R.J. Calibration of a commercial SPME device for measuring headspace concentrations of organic volatiles. Analytical Chemistry, v. 69, p.364-372,1997.

35 JUI, J. Headspace SPME: dynamics and quantitative analysis before reaching a partition equilibrium. Analytical Chemistry, v.69, n.16, p.32603266, 1997.

36 OKEYO, P. ; SNOW, N. Optimizing SPME / Gas chromatographic injections. LC-GC, v.15, p.1130-1136, 1997.

37 CURREN, M.S.S.; KING, J.W. Ethanol-modified subcritical water extraction combined with solid-phase microextraction for determining atrazine in beef kidney. Journal of Agricultural and Food Chemistry, v.49, n.5, p. 2175-2180, 2001.

38 WHITON, R.S.; ZOECKLEIN, B.W. Optimization of headspace solid phase microextraction for analysis of wine aroma compounds. American Journal of Enology and Viticulture, v.51, n.4, p.379-382, 2000.

39 PELUSIO F.; NILSSON T.; MONTANARELLA L.; TILIO R.; LARSEN B.; FACCHETTI S.; MADSEN J. O. Headspace solid-phase microextraction analysis of volatile organic sulfur compounds. In: BLACK and white truffle aroma. Journal of Agricultural and Food Chemical, v.43, p. 21382143, 1995.

40 DE LA CALLE GARCIA, D.; MAGNAGHI, S.; REICHENBAECHER, M.; DANZER, K. Systematic optimization of the analysis of wine bouquet components by solid- phase microextraction. Journal of High Resolution Chromatography, v.19, n.5, p.257-262, 1996.

41 DE LA CALLE GARCIA, D.; REICHENBAECHER, M.; DANZER, K.; HURLBECK, C.; BARTZSCH, C.; FELLER, K. H. Investigations on wine bouquet components by solid-phase microextraction-capillary gas chromatography (SPME-CGC) using different fibers. Journal of High Resolution Chromatography, v.20, n.12, p.665-668, 1997. 
42 MESTRES, M.; BUSTO, O.; GUASCH, J. Headspace solid - phase microextraction analysis of volatile sulfides and disulfides in wine aroma. Journal of Chromatography A, v.808, n. 1-2, p.211-218, 1998.

43 DE LA CALLE GARCIA, D.; REICHENBAECHER, M.; DANZER, K.; HURLBECK, C.; BARTZSCH, C.; FELLER, K. H. Use of solid - phase microextraction-capillary-gas chromatography (SPME-CGC) for the varietal characterization of wines by means of chemometrical methods. Fresenius' J. Anal. Chem., v.360, n.7-8, p.784-787, 1998.

44 DE LA CALLE GARCIA, D.; REICHENBAECHER, M.; DANZER, K.; HURLBECK, C.; BARTZSCH, C.; FELLER, K. H., Analysis of wine bouquet components using headspace solid-phase microextraction-capillary gas chromatography. Journal of High Resolution Chromatography, v.21, n.7, p.373-377, 1998.

45 VAS, G. Y.; KOTELEKY, K.; FARKAS, M.; DOBO, A.; VEKEY, K. Fast screening method for wine headspace compounds using solid - phase microextraction (SPME) and capillary GC technique. Am. J. Enol. Vitic., v.49, n.1, p.100-104,1998.

46 DE LA CALLE GARCIA, D.; REICHENBAECHER, M.; DANZER, K. Classification of wines by means of multivariate data analysis using the SPME /CGC-chromatograms of volatile aroma compounds. Vitis, v.37, n.4, p. 181-188, 1998.

47 VAS, G.; GAL, L.; HARANGI, J.; DOBO, A.; VEKEY, K. Determination of volatile aroma compounds of Blaufrankisch Wines extracted by solid phase microextraction. Journal of Chromatography Science, v.36, n.10, p. 505-510, 1998.

48 HAYASAKA, Y.; BARTOWSKY, E. J. Analysis of diacetyl in wine using solid - phase microextraction combined with gas chromatography-mass spectrometry. Journal of Agricultural and Food Chemistry, v. 47, n.2, p.612-617, 1999.

49 ONG, P. K. C.; ACREE, T. E. Similarities in the aroma chemistry of gewuerztraminer variety wines and lychee (litchi chinesis sonn.). Fruit J. Agric. Food Chem., v.47, n.2, p. 665-670, 1999.

50 VAS, G. Characterization of beer samples using SPME/capillary GC analysis. Supelco Reporter, v.16, n.4, p.7,1997.

51 JELEN, H.H.; WLAZLY, K.; WASOWICZ, E.; KAMINSKI, E. Solid-phase microextraction for the analysis of some alcohols and esters in beer: comparison with static headspace method. Journal of Agricultural and Food Chemistry, v.46, n.4, p.1469-1473, 1998.

52 ENTON, Z. Determining volatiles in beer with automated SPME and GC/ MS/ECD. Chem. N. Z., v.62, n.2, p.41-43, 1998.

53 LAY-KEOW, N.G.; HUPE, M.; HARNOIS, J.; MOCCIA, D. Characterization of commercial vodkas by solid-phase microextraction and gas chromatography/mass spectrometry analysis. Journal of Science Food 
Agricultural, v.70, n.3, p. 380-388, 1996.

54 LEE, K.Y.M.; PATERSON A.; BIRKMYRE, L.; PIGGOTT, J.R. Headspace congeners of blended Scotch whiskies of different product categories from SPME analysis. Journal of the Institute of Brewing, v.107, n.5, p. 315-332, 2001.

55 PENTON, Z. Flavor volatiles. In: A FRUIT beverage with automated SPME. Food Testing \& Analysis, v.2, n.3, p. 16-18, 1996.

56 MATICH, A. J.; ROWAN, D. D.; BANKS, N. H. Solid phase microextraction for quantitative headspace sampling of apple volatiles. Analytical Chemistry, v.68, n.23, p.4114-4118, 1996.

57 CONSTANT, M.; COLLIER, J. Headspace gas chromatography profiles of fruit-flavored malt beverages using solid phase microextraction. J. Am. Soc. Brew. Chem., v. 55, n.3, p.112-118, 1997.

58 SUNG, J.; GARDNER, B. D.; HOLLAND, J. F.; BEAUDRY, R. M. Rapid analysis of volatile flavor compounds in apple fruit using SPME and GC/ Time-of-Flight mass spectrometry. Journal of Agricultural and Food Chemistry, v.45, p.1801-1807, 1997.

59 JIA, M.; ZHANG, Q. H.; MIN, D. B. Optimization of solid phase microextraction analysis for headspace flavor compounds of orange juice. Journal of Agricultural and Food Chemistry, p.46, n.7, p.27442747, 1998.

60 IBANEZ, E.; LOPEZ-SEBASTIAN, S.; RAMOS, E.; TABERA, J.; REGLERO, $G$. Analysis of volatile fruit components by headspace solid-phase microextraction. Food Chemistry, v.63, n.2, p.281-286, 1998.

61 SERVILI, M.; SELVAGGINI, R.; BEGLIOMINI, A. L.; MONTEDORO, G. F. Effect of thermal treatment in the headspace volatile compounds of tomato juice. Dev. Food Sci., v. 40, p.315-330, 1998.

62 SONG, JUN; FAN, LIHUA; BEAUDRY, RANDOLPH, M. Application of solid phase microextraction and gas chromatography/time-of-flight mass spectrometry for rapid analysis of flavor volatiles in tomato and strawberry fruits. Journal of Agricultural and Food Chemistry, v.46, n.9, p.37213726, 1998.

63 JORDAN, M.J.; TILLMAN, N.; MUCCI, B. ; LAENCINA, J. Using HS-SPME to determine the effects of reducing insoluble solids on aromatic composition of orange juice. Lebensmittel Wissenschaft und Technologie, v. 34, n. 4, p.244-250, 2001.

64 ClasAdONTE, M.T.; GIUfFRIDA, R.; ZERBO, A.; CIRAOLO, L.; Determination of benzene and toluene in fruit juice by solid phase microextraction (SPME) and HPLC. Rassegna Chimica, v.49, n.5, p.345352, 1997.

65 COSTA FREITAS, A. M.; PARREIRA, C.; VILAS-BOAS, L. The use of an electronic aroma-sensing device to assess coffee differentiation and 
comparison with spme gas chromatography/mass spectrometry aroma patterns. Journal of Food Composition and Analysis, v.14, p. 513-522, 2201.

66 PAN, L.; ADAMS, M.; PAWLISZYN, J. Determination of fatty acids using solid phase microextraction. Analytical Chemistry, v. 67, n.23, p. 4396403, 1995.

67 MARSILI, R. T. Comparison of solid - phase microextraction and dynamic headspace methods for the gas chromatographic-mass spectrometric analysis of light-induced lipid oxidation products in milk. Journal of Chromatography Science, v.37, n.1, p.17-23, 1999.

68 CHIN, H. W.; BERNHARD, R. A.; ROSENBERG, M. Solid phase microextraction for cheese volatile compound analysis. Journal of Food Science, v.61, p.1118-1128, 1996.

69 JOU, K. D.; HARPER, W. J. Pattern recognition of Swiss cheese aroma compounds by SPME/GC and an electronic nose. Milchwissenschaft, v.53, n.5, p. 259-263, 1998.

70 GUIDOTTI, M.; VITALI, M., Identification of volatile organic compounds present in different honeys through SPME and GC/MS. Ind. Aliment., v.37, n.368, p.351-353, 1998.

71 MAZZINI, F.; BARSANTI, C.; SABA, A.; RAFFAELLI, A.; PUCCI, S.; SALVADORI, $P$. Investigation of olive oil volatile fraction by headspace SPME-GC/MS. Italian Food and Beverage Technology, v.21, p.32-34, 2000.

72 RUIZ, J.; CAVA, R.; VENTANAS, J.; JENSEN, M. T. Headspace Solid Phase Microextraction for the Analysis of Volatiles in a Meat Product: Dry-Cured Iberian Ham. Journal of Agricultural and Food Chemistry, v.46, n.11, p.4688-4694, 1998.

73 HAWTHORNE, S. B.; MILLER, D. J.; PAWLISZYN, J.; ARTHUR, C. L. Solventless determination of caffeine in beverages using solid phase microextraction with fused-silica fibers. Journal of Chromatography, v.603, p. 185, 1992.

74 YANG, M.J.; ORTON, M. L.; PAWLISZYN, J. Quantitative determination of caffeine in beverages using a combined SPME-GC/MS method. Journal of Chemical Education, v.74, n.9, p.1130-1132, 1997.

75 CONTE, L. S.; BORTOLOMEAZZI, R.; MORET, S.; SABATINI, A. G.; Marcazzan, G. L. Application of solid - phase microextraction in the determination of phenol in honey. Riv. Sci. Aliment., v.26, n.3/4, p.97102, 1998.

76 GANDINI, N.; RIGUZZI, R. Headspace solid phase microextraction analysis of methyl isothiocyanate in wine. Journal of Agricultural and Food Chemistry, v.45, n.8, p.3092-3094, 1997.

77 FLAK, W.; TSCHEIK, G. Determination of styrene in wine by solid phase 
micro extraction technology and GC-MS analysis. Mitt. Klosterneuburg, v.47, n.4, p.117-123, 1997.

78 VOlANTE, M.; CATTANEO, M.; BIANCHI, M.; ZOCCOLA, G. Some applications of solid phase micro extraction (SPME) in the analysis of pesticide residues in food. Journal of Environmental Science and Health B (Pesticides, Food Contaminants and Agricultural Wastes), v.B33, n.3, p.79-292, 1998.

79 JIMDNEZ, J. J.; BERNAL, J. L.; DEL NOZAL, M. J.; MARTIN, M. T.; MAYORGA, A. L. Solid phase microextraction applied to the analysis of pesticide residues in honey using gas chromatography with electroncapture detection. Journal of Chromatography A, v. 829, n .1-2, p.269277, 1998.

80 GALARINI, R.; COSSIGNANI, L.; SIMONETTI, M.S.; RUFFINI, N.; MARCHETTI, C.; LUNEIA, R.; DAMIANI, P. Rapid determination of pesticide residues in honey by SPME-HRGC-NPD and SPME-HRGCECD. In: ASSEMBLEA ANNUALE DEI SOCI ED EVENTO SCIENTIFICO. SALSOMAGGIORE, 1., Italy, 13 Novembre, 1998. Selezione-Veterinaria, Suppl., p. s417-s422, 2000.

81 VOLANTE, M.; GALARINI, R.; MIANO, V.; CATTANEO, M.; PECORELLI, I.; BIANCHI, M.; MARINONI, M.T.; COSSIGNANI, I.; DAMIANI, P. A SPME-GCMS approach for antivarroa and pesticide residues analysis in honey. Chromatographia, v. 54, n.3/4, p. 241-246, 2001.

82 CAO, C.F.; WANG, Z.; URRUTY, L.; POMMIER, J.J.; MONTURY, M. Focused microwave assistance for extracting some pesticide residues from strawberries into water before their determination by SPME/HPLC/DAD. Journal of Agricultural and Food Chemistry, v.49, n.11, p. 5092-5097, 2001.

83 FERNANDEZ, M.; PADRON, C.; MARCONI, L.; GHINI, S.; COLOMBO, R.; SABATINI, A.G.; GIROTTI, S. Determination of organophosphorus pesticides in honeybees after SPME. Journal of Chromatography $\mathbf{A}$, v.922, n.1-2, p. 257-265,2001.

84 HU, R.; HENNION, B.; URRUTY, L.; MONTURY, M. SPME of pesticide residues from strawberries. Food Additives and Contaminants, v.16, n.3, p.111-117, 1999.

85 WANG, Z.H.I.; HENNION, B.; URRUTY, L.; MONTURY, M.; WANG, Z. Solidphase microextraction coupled with high performance liquid chromatography: a complementary technique to solid-phase microextraction-gas chromatography for the analysis of pesticide residues in strawberries. Food Additives and Contaminants, v. 17, n. 11, p. 915-923, 2000.

86 WENNRICH, L.; POPP, P.; KOLLER, G.; BREUSTE, J. Determination of organochlorine pesticides and chlorobenzenes in strawberries by using accelerated solvent extraction combined with sorptive enrichment and gas chromatography/mass spectrometry. Journal of AOAC International, 
v.84, n.4, p.1194-1201, 2001.

87 VITALI, M.; GUIDOTTI, M.; GIOVINAZZO, R.; CEDRONE, O. Determination of pesticide residues in wine by SPME and GC/MS for consumer risk assessment. Food Additives and Contaminants, v.15, n.3, p.280-287, 1998.

88 CORREIA, M.; DELERUE, M. C.; ALVES, A.; CAMOES, M.F. Development of a SPME-GC-ECD methodology for selected pesticides in must and wine samples. Fresenius Journal of Analytical Chemistry, v.369, n.7-8, p.647-651, 2001.

89 WENNRICH, L.; POPP, B. B. Determination of organochlorine pesticides and chlorobenzenes in fruit and vegetables using subcritical water extraction combined with sorptive enrichment and CGC-MS. Journal of Chromatography, v.53, Part 2, Suppl., p.S380-S386, 2001.

90 ROHRIG, L.; MEISCH, H.U. Application of SPME for the rapid analysis of chlorinated organics in breast milk. Fresenius Journal of Analytical Chemistry, v.366, n.1, p.106-111, 2000.

91 DUCRUET, V.; FOURNIER, N.; SAILLARD, P.; FEIGENBAUM, A.; GUICHARD, E. Influence of packaging on the aroma stability of strawberry syrup during shelf life. Journal of Agricultural and Food Chemistry, v.49, n. 5, p.2290-2297, 2001.

92 MARSILI, R.T. Shelf-life prediction of processed milk by solid-phase microextraction, mass spectrometry, and multivariate analysis. Journal of Agricultural and Food Chemistry, v.48, n.8, p.3470-3475, 2000.

93 BRITO, E.S.D.E.; PEZOA GARCIA, N.H.; AMANCIO, A.C.; VALENTE, A.L.P.; PINI, G.F.; AUGUSTO, F. Effect of autoclaving cocoa nibs before roasting on the precursors of the Maillard reaction and pyrazines. International Journal of Food Science and Technology, v.36, n.6, p. 625-630, 2001.

94 SIDES, A.; ROBARDS, K.; HELLIWELL, S.; MIN, A. Changes in the volatile profile of oats induced by processing. Journal of Agricultural and Food Chemistry, v.49, n.5, p.2125-2130, 2001.

95 SERVILI, M.; SELVAGGINI, R.; TATICCHI, A.; BEGLIOMINI, A.L.; MONTEDORO, G. Relationships between the volatile compounds evaluated by solid phase microextraction and the thermal treatment of tomato juice: optimization of the blanching parameters. Food-Chemistry, v.71, n. 3, p.407-415, 2000.

96 PALMA-HARRIS, C.; MCFEETERS, R.F.; FLEMING, H.P. Solid-phase microextraction (SPME) technique for measurement of generation of fresh cucumber flavor compounds. Journal of Agricultural and Food Chemistry, v.49, n.9, p.4203-4207, 2001.

97 XUETONG, F.; GATES, R.A. Degradation of monoterpenes in orange juice by gamma radiation. Journal of Agricultural and Food Chemistry, v.49, n.5, p.2422-2426, 2001. 
98 TOMAINO, R.M.; PARKER, J.D.; LARICK, D.K. Analysis of free fatty acids in whey products by solid-phase microextraction. Journal of Agricultural and Food Chemistry, v.49, n.8, p.3993-3998, 2001.

99 NONATO, E.A.; CARAZZA, F.; SILVA, F.C.; CARVALHO, C.R.; CARDEAL, Z. de $L$. A headspace solid-phase microextraction method for the determination of some secondary compounds of Brazilian sugar cane spirits by gas chromatography. Journal of Agricultural and Food Chemistry, v.49, n.8, p.3533-3539, 2001.

100 JONES, P.R.H.; EWEN, R.J.; RATCLIFFE, N.M. Simple methods for the extraction and identification of amine malodors from spoiled foodstuffs. Journal of Food Composition and Analysis, v.11, n.3, p.274-279, 1998.

101 NAKAI, S.; ZHI, H.W.; NAKAMURA, S.; OGAWA, M.; DOU, J.; OGIHARA, H.; HORIMOTO, Y.; NAKAI, E.; SKURA, B.J. An automated analytical system for quality assurance of foods by applying a new classification method to chromatographic data. Leatherhead Food RA Food Industry Journal, v.2, n.4, p.310-323, 1999.

102 JELEN, H.H.; OBUCHOWSKA, M.; ZAWIRSKA-WOJTASIAK, R.; WASOWICZ, E. Headspace solid-phase microextraction use for the characterization of volatile compounds in vegetable oils of different sensory quality. Journal of Agricultural and Food Chemistry, v.48, n.6, p.2360-2367, 2000.

103 WADA, S.A.D. Lipid analysis of PUFA in the new millennium and future trends. Japan Journal of Oleo Science, v.50, n.5, p.329-338, 2001.

104 VAlENTE, A. L. P.; AUGUSTO, F.; MONTERO, L.; DA ROCHA, E. C.; P.AWLISZYN, J. Application of SPME (solid phase micro-extraction) to the analysis of potable water from three locations in the state of Sao Paulo. Quimica Nova, v. 21, n.6, p.804-806, 1998.

105 JIA, J.; HE, Y.; FANG, H.; HUANG, J.; ZHOU, S. Study on headspace solid - phase microextraction for determination of chloroform in drinking water. Huanjing Kexue, v.19, n.4, p.79-87,1998.

106 GIUFFRIDA, R.; CLASADONTE, M.T.; ZERBO, A. Determination of benzene and toluene in vegetable oils by SPME/HPLC. Journal of Commodity Science, v.38, n.1, p.3-14, 1999.

107 VERGNAIS, L.; MASSON, F.; MONTEL, M.C.; BERDAGUE, J.L.; TALON, $R$. Evaluation of solid-phase microextraction for analysis of volatile metabolites produced by staphylococci. Journal of Agricultural and Food Chemistry, v.46, n.1, p.228-234, 1998.

108 OGIHARA, H.; HORIMOTO, Y.; ZHI, H.W.; SKURA, B.J.; NAKAI, S. Solid phase microextraction/gas chromatography of Salmonella-infected beef. Journal of Agricultural and Food Chemistry, v.48, n.6, p.2253-2259, 2000.

109 WYLLIE, S.G.; FELLMAN, J.K. Formation of volatile branched chain esters 
in bananas (Musa sapientum L.). Journal of Agricultural and Food Chemistry, v.48, n.8, p.3493-3496, 2000.

110 VIANNA, E.; EBELER, S.E. Monitoring ester formation in grape juice fermentations using solid phase microextraction coupled with gas chromatography-mass spectrometry. Journal of Agricultural and Food Chemistry, v.49, n.2, p.589-595,2001.

111 NILSSON, T.; LARSEN, T.O.; MONTANARELLA, L.; MADSEN, J.O. Application of head-space solid-phase microextraction for the analysis of volatile metabolites emitted by Penicillium species. Journal of Microbiological Methods, v.25, n.3, p.245-255, 1996.

112 WATKINS, P.J.; SHEN, Z.; WIJESUNDERA, C. Determination of volatile flavour compounds in cheese by SPME and GC/MS. Aust. J. Dairy Technol., v. 57, n.2, p.70-70, 2002.

113 GUIDOTTI, M. Determination of $\mathrm{Se}^{4-+}$ in drinkable water by solid-phase microextraction and gas chromatography/mass spectrometry. Journal of AOAC International, v.83, n.5, p.1082-1085, 2000.

114 GUIDOTTI, M.; RAVAIOLI, G. Selective determination of $\mathrm{Se}^{4+}$ and $\mathrm{Se}^{6+}$ using SPME and GC/MS. HRC, v.22, n.7, p.414-416, 1999.

115 MESTER, Z.; LAM, J.; STURGEON, R.; PAWLISZYN, J. Determination of methylmercury by solid-phase microextraction inductively coupled plasma mass spectrometry: a new sample introduction method for volatile metal species. Journal of Analytical Atomic Spectrometry, v.15, n.7, p.837-842, 2000.

116 QUEIROZ, M.E.C.; SILVA, S.M.; CARVALHO, D.; LANÇAS, F.M. Comparison between solid-phase extraction methods for the chromatographic determination of organophosphorus pesticides in water. Journal of Environmental Science and Health, B (Pesticides, Food-Contaminants-and Agricultural Wastes), v. B36, n.5, p.517-527, 2001. 